\title{
Tuberculosis among health care workers during three recent decades
}

\author{
M. Raitio, E. Tala
}

\begin{abstract}
Tuberculosis among health care workers during three recent decades. M. Raitio, E. Tala. (C) ERS Journals Ltd 2000.

ABSTRACT: Some studies have found that health care workers have an increased risk of tuberculosis, whereas other studies have reported the opposite. This study examined data of Finnish health care workers (HCWs) for the incidence of tuberculosis disease.

Cases of occupational tuberculosis in Finland were analysed over a period of $30 \mathrm{yrs}$ (1966-1995). Control subjects were all other incident tuberculosis cases at working age. The material thus obtained included 658 people with notified occupational tuberculosis, and 56,146 control cases. The authors studied incidence, and age specific rate, as well as their trends.

The incidence of tuberculosis among health care workers decreased from 57.9 to 6.1 per 100,000 and the corresponding figures among control subjects decreased from 156.8 to 9.1 per 100,000 . The overall risk in health care workers was lower than in the general population throughout the study period. Analysis of age specific rates revealed no age group at increased risk. The reasons are multifactorial, among them the successful tuberculosis programme, and the lack of impact of such risk factors as immigration, human immunodeficiency virus infection and drug resistance; high coverage of bacille Calmette-Guérin vaccination may also be a factor, although it is difficult to assess.
\end{abstract}

Eur Respir J 2000; 15: 304-307.

Dept of Chest Diseases, Turku University Central Hospital, Turku, Finland.

Correspondence: M. Raitio

Paimio hospital, Alvar Aallon tie 275

FIN-21540 Preitilä

Finland

Fax: 35822614300

Keywords: Health care workers tuberculosis incidence

tuberculosis risk

Received: December 311999

Accepted after revision July 111999

This study received financial support from the Finnish Anti-Tuberculosis Association Foundation.

Tuberculosis (TB) has always been a hazard for health care workers (HCWs), although this was not generally recognized before the 1950s [1]. Introduction of chemotherapy diminished the risk of infection considerably. However, there have been some disturbing recent trends: infection with human immunodeficiency virus (HIV) increases the risk of TB disease subsequent to infection [2]; altered manifestations are hampering diagnosis [3] and prolonging the time during which patients are infectious. Poor treatment practice and lack of compliance have led to an expansion of drug resistance. Immigrant patients from high-incidence countries also constitute a risk factor for HCWs in developed countries [4, 5].

Published estimates of the risk of TB infection vary according to time and geographical area, as well as exposure intensity and duration, all of which are difficult to assess; differences in risk are found between job categories and between hospitals [6-8]. The risk of TB infection has generally been considered to be higher among HCWs than in the general population. However, some recent studies in developed countries have shown the risk of the disease among HCWs to be the same as or lower than in the surrounding community [6,9-12]. On the other hand, some authors have found groups of workers with higher risk [13-17].

In Finland the rate of decrease in TB incidence during the last three decades (1966-1995) has been one of the fastest in Europe. The incidence of all forms of TB in the general population in 1966 was 150 per 100,000 , but by
1995 it had fallen to 12 per $100,000[18,19]$. This period is long enough to reflect overall changes among HCWs, and the authors have therefore studied whether the trend has been the same as in the general population.

\section{Populations and methods}

During 1966-1995, the population in Finland has increased from 4.652 million to 5.117 million $(10 \%)$ [20]. At the same time the number of people working within health care has increased from 40,039 to 197,897 (394\%).

The National Tuberculosis Register covers the whole country and is based on the statutory obligation of all physicians for notification. A case is registered if TB is confirmed bacteriologically or histologically or if the clinical findings are consistent with active TB and a full course of chemotherapy is therefore indicated. Cases are classified as pulmonary or extrapulmonary, and are registered separately in 5-yr age groups both for males and females. Notification entitles patients to have full treatment free of charge, and therefore all cases are entered into the register.

The National Register of Occupational Diseases is also based upon statutory notification, and cases of TB among $\mathrm{HCWs}$ are entitled to claim compensation if they may have been exposed at work. The register was started in 1964 and may suffer from underreporting for the first few years. The definition used for a case of TB conforms with that in the National Tuberculosis Register. 
Finland has carried out a comprehensive Bacillus Calmette-Guérin (BCG) vaccination programme since the 1950 s, and the Finnish population is one of the most comprehensively BCG-vaccinated in the world; coverage at birth is still close to $100 \%$, and revaccination has been discontinued since 1990 [21]. Therefore no annual tuberculin tests for HCWs are in use; chemoprophylaxis is very rarely used, and this policy has been adopted throughout the country. Annual chest radiograph screenings of HCWs at higher risk were discontinued gradually in the early 1990s. For primary prevention, contagious TB patients are virtually always treated in special wards and in separate rooms within chest clinics.

The study population consisted of all HCWs at working age between 1966-1995. Data were obtained from the National Board of Health and from the Ministry of Social Welfare and Health. HCWs include for example, doctors, all grades of nurses, laboratory workers, radiographic personnel, psychiatric nurses, physiotherapists, but not administrative personnel. TB cases among HCWs were obtained from the National Register of Occupational Diseases. The information included age, sex, occupation, area of residence, diagnosis, and degree of disability. The total number of notified cases of occupational TB during 1966-1995 was 711 . Fifty-one cases $(7.2 \%)$ were excluded because they were not working in the field of health care, the majority of them coming from the mining industry. Two further cases were excluded because of age $>64$ yrs (67 and $73 \mathrm{yrs}$ ). Thus the study cases consisted of 658 persons ( 95 males, 563 females) working within health care who had occupational TB.

The control population comprised all other people in the age range 15-64 yrs during the same period. This number was obtained from Statistics Finland, subtracting the number of HCWs so that the HCW population and the control population were separated. The control cases consisted of TB patients who were newly notified during 1966-1995 in the age range 15-64 yrs, subtracting the number of HCWs.

In order to discount yearly fluctuations, the cases were examined in periods of 5 yrs. The number of HCWs was calculated as a mean for each 5-yr period. To begin with, the occupational risk of TB disease was estimated by comparing incidence in HCWs and in the control population. On the basis of these results, both HCWs and the control subjects were analysed separately in age groups of 15-19, $20-39,40-59$ and $60-64$ yrs. Risk analyses were performed to obtain age-specific rates covering the total study period and both age- and sex-specific rates covering the years 1981-1995. Statistical analyses were performed using SAS (Statistical Analysis System) software, release 6.12 for Windows (SAS Institute, Cary, NC, USA). The differences between the populations were tested with the Chi-squared test and Fisher's exact test, and the common relative risks (RR) were calculated.

\section{Results}

The peak TB incidence in HCWs in Finland was seen during 1971-1975, with 184 cases, and the average annual incidence was 57.9 per 100,000 . Since then, incidence has diminished in both groups, but in HCWs it has remained slightly lower than in the control population (table 1).

Age-specific rates of TB during the whole study period showed that the common RR of the disease was 0.22 among the 20-39 yr age group, 0.09 among the 40-59 yr age group, and 0.17 among the $60-64$ yr age group (table 2 ). These figures demonstrate that the overall risk of TB in HCWs was lower than in the control population. There was not an increased rate of disease among young HCWs, although a preliminary analysis of the age at which TB was contracted in HCWs showed that young age groups may have an increased level of risk: among HCWs $71 \%$ of all cases (466/658) were diagnosed at the age of 20-39 $\mathrm{yrs}$, the corresponding figure being $31 \%(17,190 / 56,146)$ among control subjects.

If all of the age groups are studied together, the risk of TB was consistently significantly lower for HCWs, but the difference seemed to decrease towards the end of the study period (table 3). Maximum likelihood analysis of variance during 1981-1995 revealed that sex had no effect on the risk of TB. Age was the strongest factor, but it failed to reach statistical significance even during 1981-1985, and after that period its effect weakened even further.

\section{Discussion}

The authors have studied the overall risk of TB disease among HCWs compared to the general population of corresponding age during 1966-1995. The results demonstrate that the overall risk of TB among the total HCW population was lower than among the non-HCW population. The reasons for this are very probably multifactorial.

Finland is a technically advanced country with a high level of health care and social care. The TB programme has been effective: during the study period the incidence of TB has diminished by $>90 \%[18,19]$. Compared with many

Table 1. - The number of annual tuberculosis (TB) cases and the annual incidence per 100,000, with annual mean numbers for health care workers and the control population

\begin{tabular}{|c|c|c|c|c|c|c|}
\hline \multirow{2}{*}{ Period } & \multicolumn{3}{|c|}{ Health care workers } & \multicolumn{3}{|c|}{ Control population } \\
\hline & TB cases & Incidence & Mean population per year & TB cases & Incidence & Mean population per year \\
\hline $1966-1970$ & 76 & 33.8 & 45029 & 23697 & 156.8 & 3022971 \\
\hline $1971-1975$ & 184 & 57.9 & 63541 & 14649 & 95.2 & 3076659 \\
\hline 1976-1980 & 158 & 39.3 & 80384 & 8612 & 54.9 & 3134816 \\
\hline $1981-1985$ & 115 & 24.6 & 93473 & 5073 & 31.5 & 3218001 \\
\hline 1986-1990 & 69 & 8.7 & 157920 & 2646 & 16.6 & 3190940 \\
\hline 1991-1995 & 56 & 6.1 & 184708 & 1469 & 9.1 & 3213420 \\
\hline Total & 658 & & & 56146 & & \\
\hline
\end{tabular}

Five-year number of TB cases (in the "TB cases" column) was divided by five and then divided by the "mean population per year" value to compute the annual incidence value. 
Table 2. - Common relative risk (CRR) of tuberculosis and $95 \%$ confidence interval $(\mathrm{Cl})$ in health care workers by age

\begin{tabular}{|c|c|c|c|c|c|c|c|c|c|c|c|c|}
\hline \multirow{2}{*}{ Period } & \multicolumn{3}{|c|}{ Age $15-19$ yrs } & \multicolumn{3}{|c|}{ Age $20-39$ yrs } & \multicolumn{3}{|c|}{ Age $40-59$ yrs } & \multicolumn{3}{|c|}{ Age $60-64$ yrs } \\
\hline & CRR & $95 \%$ CI & p-value & CRR & $95 \%$ CI & $\mathrm{p}$-value & CRR & $95 \%$ CI & $p$-value & CRR & $95 \% \mathrm{CI}$ & p-value \\
\hline 966 & $*$ & - & - & 0.03 & 0.0 & 0 & 0.05 & 0.0 & & 0.32 & 0.02 & 0.214 \\
\hline $1971-$ & * & - & - & 0.11 & 0.0 & 1 & 0.04 & 0.0 & 1 & 0.11 & $0.01-1.81$ & 0.035 \\
\hline 30 & 0.05 & $0.00-0.81$ & 0.002 & 0.57 & 0.2 & & 0.19 & 0.0 & & $*$ & - & - \\
\hline $981-1985$ & * & - & - & 0.15 & $0.05-0.48$ & 0.001 & 0.10 & $0.03-0.30$ & 0.001 & 0.09 & $0.01-1.39$ & 0.016 \\
\hline $1986-1990$ & $*$ & - & - & 0.30 & $0.07-1.20$ & 0.069 & 0.13 & $0.03-0.54$ & 0.001 & 0.15 & $0.01-2.35$ & $0.034^{\#}$ \\
\hline 1991-1995 & * & - & - & 0.34 & $0.08-1.39$ & 0.115 & 0.23 & $0.06-0.93$ & 0.025 & 0.30 & $0.02-4.79$ & 0.195 \\
\hline Total & $*$ & & & 0.22 & $0.14-0.33$ & & 0.09 & $0.05-0.17$ & & 0.17 & $0.05-0.58$ & \\
\hline
\end{tabular}

*: data insufficient for analysis; ${ }^{\#}$ : Fisher's exact test.

other studies from the developed world, the incidence of TB in HCWs used to be higher in Finland, but during the past decade (1985-1995) it has been decreased to a low level. For comparison, incidence figures of 9.4 per 100,000 in hospital employees and over 12 per 100,000 in the general population for all forms of TB were seen during 1983 and 1984 in North Carolina, USA [11]. In Scotland, (UK), during 1978-1983, the incidence of pulmonary TB was 11 per 100,000 for HCWs and 20 per 100,000 for the general population [9]. In England and Wales, (UK), the overall incidence of pulmonary TB in 1980-1984 for all hospital employees was only 3.4 per 100,000 [22]; for the general population in the age range $15-64$ yrs, the figure was 9.9 per 100,000 . These studies contain no information about the age distribution of cases. The current results indicate that age does not have an important impact on TB risk.

Risk factors prevailing in many countries are practically absent in Finland. The number of immigrants is low, and the majority of them have come from countries with a low incidence of TB. At the end of 1995, there were 106,303 people (2.1\% of total population) resident in Finland with a registered birth place abroad, the majority of whom were from Sweden [20]. In this study, hardly any cases of TB found among HCWs have come from high-incidence countries. The country of origin therefore has little impact on TB incidence among HCWs or the control population, unlike in Canada, where foreign-born workers constituted $59 \%$ of the cases among HCWs [23]. The prevalence of HIV infection in Finland is also low; only 72 new cases of HIV infection were found in 1995 (incidence 2.1 per 100,000 in the 15-64 yr age group). Multidrug-resistant $\mathrm{TB}$ is very rare; in 1995 only one case with resistance to both isoniazid (INH) and rifampicin was seen in Finland.

The most cost-effective intervention against TB among HCWs has not been agreed upon. Annual tuberculin testing has been suggested as the gold standard. However,

Table 3. - Common relative risk (CRR) of tuberculosis in health care workers by period, all age groups

\begin{tabular}{lccc}
\hline Period & CRR & $95 \%$ CI & p-value \\
\hline $1966-1970$ & 0.05 & $0.02-0.13$ & 0.001 \\
$1971-1975$ & 0.08 & $0.04-0.17$ & 0.001 \\
$1976-1980$ & 0.46 & $0.23-0.92$ & 0.001 \\
$1981-1985$ & 0.12 & $0.06-0.26$ & 0.001 \\
$1986-1990$ & 0.19 & $0.08-0.49$ & 0.001 \\
$1991-1995$ & 0.28 & $0.11-0.72$ & 0.003 \\
\hline
\end{tabular}

95\% CI: 95\% confidence interval. this is not practicable, since all HCWs in Finland will necessarily be BCG-vaccinated or tuberculin positive. Therefore, INH prophylaxis is used only exceptionally. Controlled studies on the tuberculosis risk of BCG-vaccinated HCWs have not been performed, but it has been calculated that even with a low efficacy, BCG vaccination might be as effective as annual tuberculin testing and INH prophylaxis [24]. The current results support this view.

HCWs as a selected group may also have better a priori infection resistance against TB. They are more conscious about health matters than average, which influences their behaviour in areas such as nutrition and smoking. This hypothesis is in line with the results of a Canadian study: alcohol abuse and malnutrition were found significantly less frequently in HCWs than in control subjects [12].

Underreporting cannot explain the difference in favour of health care workers but cases resulting from endogenous reactivation after working age are not included. However, the impact is the same on both groups. On the other hand there is evidence that a significant proportion of tuberculosis disease is due to recent contact [2, 5, 25], most probably originating in situations with heavy exposure. This model presumably also applies to tuberculosis exposure in health care [26]. It is known that unsuspected infectious cases may increase the risk of infection more than 6-fold [27]. The present results show the overall risk alone. However, major differences have been found elsewhere between groups of workers: for example, annual incidence ranged from 0.6 per 100,000 for those not involved in patient care to 108 per 100,000 for mortuary attendants [22]. Consequently, the authors' next analysis will be concentrated on exploring the differences between job categories, and on identifying potential risk groups.

Acknowledgements. The authors thank A. Kaljonen, for performing the statistical analyses, and $\mathrm{K}$. Battarbee, for revision of the text.

\section{References}

1. Sepkowitz KA. Tuberculosis and the health care worker: a historical perspective. Ann Intern Med 1994; 120: 7179 .

2. Daley CL, Small PM, Schecter GF, et al. An outbreak of tuberculosis with accelerated progression among persons infected with the human immunodeficiency virus: an analysis using restriction-fragment-length polymorphisms. N Engl J Med 1992; 326: 231-235. 
3. Barnes PF, Bloch AB, Davidson PT, Snider DE Jr. Tuberculosis in patients with human immunodeficiency virus infection. N Engl J Med 1991; 324: 1644-1650.

4. Davies PDO. Tuberculosis and migration. Eur Respir Mon 1997; 4: 68-87.

5. Tornieporth NG, Ptachewich Y, Poltoratskaja N, et al. Tuberculosis among foreign-born persons in New York City 1992-1994: implication for tuberculosis control. Int J Tuberc Lung Dis 1997; 6: 528-535.

6. Menzies D, Fanning A, Yuan L, Fitzgerald M. Tuberculosis among health care workers. N Engl J Med 1995; 332: 92-98.

7. Aitken ML, Anderson KM, Albert RK. Is the tuberculin screening program of hospital employees still required? Am Rev Respir Dis 1987; 136: 805-807.

8. Bailey TC, Fraser VJ, Spitznagel EL, Dunagan WC. Risk factors for a positive tuberculin skin test among employees of an urban, midwestern teaching hospital. Ann Intern Med 1995; 122: 580-585.

9. Capewell S, Leaker AR, Leitch AG. Pulmonary tuberculosis in health service staff - is it still a problem? Tubercle 1988; 69: 113-118.

10. Loughrey C, Riley M, Varghese G. Tuberculosis among national health service employees. Am Rev Respir Dis 1992; 145 (Suppl.): A103.

11. Price LE, Rutala WA, Samsa GP. Tuberculosis in hospital personnel. Infection Control 1987; 8: 97-101.

12. Pleszewski B, FitzGerald JM. Tuberculosis among health care workers in British Columbia. Int J Tuberc Lung Dis 1998; 2: 898-903.

13. Barret-Connor E. The epidemiology of tuberculosis in physicians. JAMA 1979; 241: 33-38.

14. Geiseler PJ, Nelson KE, Crispen RG, Moses VK. Tuberculosis in physicians: a continuing problem. Am Rev Respir Dis 1986; 133: 773-778.

15. Malasky C, Jordan T, Potulski F, Reichman LB. Occu- pational tuberculous infections among pulmonary physicians in training. Am Rev Respir Dis 1990; 142: 505-507.

16. Sepkowitz KA. AIDS, tuberculosis and the health care worker. Clin Infect Dis 1995; 20: 232-242.

17. Babus V. Tuberculosis morbidity risk in medical nurses in specialized institutions for the treatment of lung diseases in Zagreb. Int J Tuberc Lung Dis 1997; 1: 254-258.

18. Tala E, Viljanen M. Mycobacterial infections in Finland. Scand J Infect Dis 1995; Suppl. 98: 7-8.

19. Global tuberculosis control, WHO/TB/97.225. Geneva 1997.

20. Statistics Finland. Statistical Yearbook of Finland, 1996. Helsinki, Statistics Finland, 1996.

21. Tala-Heikkilä MM, Tuominen JE, Tala EOJ. Bacillus Calmette-Guérin revaccination questionable with low tuberculosis incidence. Am J Respir Crit Care Med 1998; 157: 1324-1327.

22. Lunn JA, Mayho V. Incidence of pulmonary tuberculosis by occupation of hospital employees in the National Health Service in England and Wales 1980-84. J Soc Occup Med 1989; 39: 30-32.

23. Ashley MJ, Wigle WD. The epidemiology of active tuberculosis in hospital employees in Ontario, 1966-1969. Am Rev Respir Dis 1971, 104: 851-860.

24. Greenberg PD, Lax KG, Schechter CB. Tuberculosis in house staff. A decision analysis comparing the tuberculin screening strategy with the BCG vaccination. Am Rev Respir Dis 1991; 143: 490-495.

25. Small PM, Hopewell PC, Singh SP, et al. The epidemiology of tuberculosis in San Francisco. $N$ Engl J Med 1994; 330: 1703-1709.

26. Markowitz SB. Epidemiology of tuberculosis among health care workers. Occup Med 1994; 9: 589-608.

27. Craven RB, Wentzel RP, Atuk NO. Minimizing tuberculosis risk to hospital personnel and students exposed to unsuspected disease. Ann Intern Med 1975; 82: 628-632. 